\title{
UNDERWATER OBSERVATIONS ON THE SWIMMING OF MARINE ZOOPLANKTON
}

\author{
By Richard Bainbridge \\ Department of Zoology and Comparative Anatomy, Oxford
}

(Text-figs. I-4)

Many experiments have been made in the laboratory by different workers to study the swimming behaviour of plankton animals in relation to light and other factors. At the present time the special apparatus described by Hardy \& Bainbridge (I95I) is being used for a study of vertical migration, and other experimental work on the inter-relationships of zooplankton and phytoplankton (Bainbridge, I949) is also in progress. Both this type of work and current theories (see Cushing, I95I) on the migrations of zooplankton make it of some consequence to learn the actual nature of the movements of these animals in the sea itself; and it is of special importance to compare their swimming behaviour in the different types of apparatus with their behaviour in the sea.

Dammant (I92I), whilst hanging below a ship during salvage operations, had already made interesting observations on mackerel feeding upon members of the plankton and shown that a diver could see quite small plankton animals under natural conditions; and Beebe (I935), making descents in the bathysphere, had frequently remarked on the visibility of plankton, although his primary aim was the observation of larger forms such as fish.

Simple diving helmets as commonly used in warmer seas are not suitable for sustained observations in colder waters: a more protective and elaborate diving suit is required. Professor Hardy, with whom I was working under a Leverhulme Research Grant, consequently approached Messrs Siebe, Gorman and Company, and their assistance was most generously and freely given. They provided training in the use of various types of diving gear and made a loan for the greater part of the summer of that type of gear which was finally decided to be most convenient for the work.

I am deeply indebted to Messrs Siebe, Gorman and Co., whose provision of training and loan of equipment made the work possible; to Professor A. C. Hardy, who gave every encouragement and who made the time and facilities available; and to Muriel C. Morris, and the staff and boat crews of the Millport Marine Station upon whom my safety depended. 


\section{EQUIPMENT AND METHODS}

The gear chosen was a modified compressed-air breathing apparatus together with a two-piece frog suit. The breathing apparatus had the normal face piece and a demand valve on the harness, but had a rubber air hose connected to a reducer valve on large ( 165 cu.ft.) compressed-air cylinders on the shore. The hose could be employed as a life-line and the standard cylinders were of greater capacity and were more easily replaced when used than the small cylinders usually carried on the diver's back. The hose allowed of quite sufficient movement for the type of observing desired and, with practice, swimming with foot flippers was possible, while more weights and the use of heavy boots allowed for walking on the bottom.

The work was performed at the Millport Marine Station and tours of observation of three kinds were tried. First, the observer simply walked down the shore to a suitable depth. This involved moving amongst rocks and in the seaweed zone and stirring up a good deal of detritus, with the result that viewing was sometimes made rather difficult. The site chosen for this method was sheltered and still. Secondly, the observer went down a ladder from Keppel Pier directly into deeper water with a hard shingly bottom. The water here was generally clearer but was without tidal movement only for very limited times during the day, whereas at the first site it was still for much longer. Thirdly, he was lowered to a suitable depth in a bosun's chair over the side of the research ship 'Calanus', which was either anchored or drifting over much deeper water. All these methods could be attempted only when weather and tidal conditions were exactly right and this naturally greatly limited the scope of the work. A fairly clear sky, with sun if possible, little wind and slack water were found to be most convenient. Thick woollen clothing allowed tours of up to $40 \mathrm{~min}$. duration in water of $6.5^{\circ} \mathrm{C}$. without very great discomfort.

Under suitable conditions it was found easy to see and recognize many copepods. Calanus finmarchicus was visible up to 4 or $5 \mathrm{ft}$. away in clear water, while amongst the smaller forms those more opaque, such as Temora and Centropages spp., were visible up to a foot away or even more. The clearest views could be seen by looking about $10^{\circ}$ either to the left or to the right of the bright patch formed by the sun on the surface of the water. In this manner a sort of dark ground illumination is obtained and even the most transparent forms stand out very clearly. By crouching or standing it is possible to follow vertical movements of about $\mathrm{Io} \mathrm{ft}$. in extent while with the flippers greater distances are feasible, although the observer's movement is then more erratic and actual distances less easy to judge with accuracy. Chains of diatoms such as Thalassiosira and Skeletonema spp. and even individuals of larger species, such as Coscinodiscus, were frequently visible as occasionally were such flagellates as Noctiluca and Phaeocystis. Need for sufficient sunlight 
naturally limits good viewing to the more surface waters and observations were not generally made at a greater depth than $20 \mathrm{ft}$. Altogether twelve descents were made over a period of about 5 weeks.

\section{OBSERVATIONS}

In the Clyde Sea area the spring brood of Calanus is often to be found in large numbers in the surface layers throughout the $24 \mathrm{hr}$. and is therefore particularly suitable for investigation. It does not, of course, follow that the behaviour of this brood, under these conditions of lighting, represents the normal behaviour of the copepod which is at other times of the year found in much deeper layers (at least $50 \mathrm{~m}$. down); but it may be allowed as an indication of the probable type of behaviour at these greater depths, where observation is not yet possible.

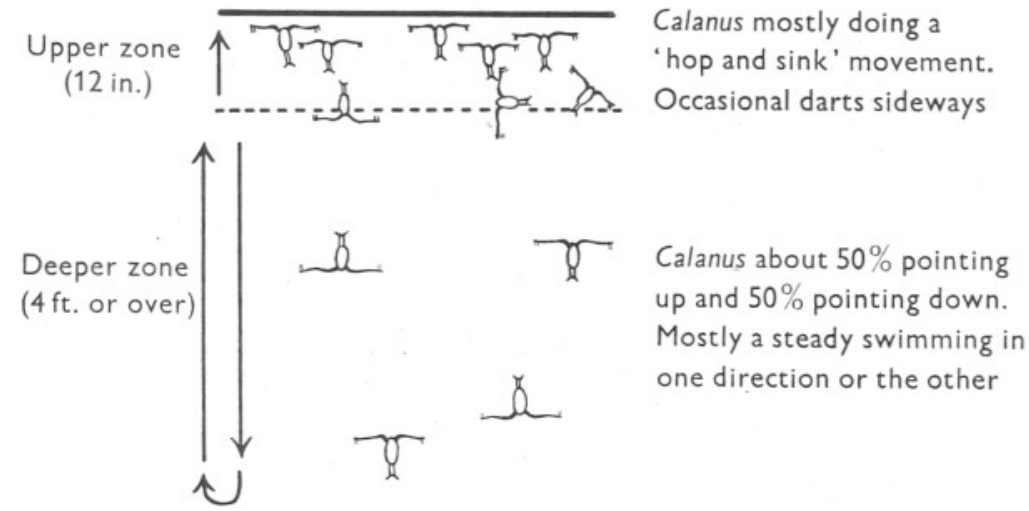

Fig. I. Distribution of 'surface' Calanus in upper water layers.

Two zones of differing behaviour are clearly recognizable in the spring Calanus (Fig. I). In the upper I 2 in. of water there is a high concentration of animals (up to as many as Io/sq.ft. of surface) and there is a continuous gentle sinking and swimming up again vertically within this zone. Occasionally violent oblique or horizontal darts of several feet may occur, especially when two or more animals come close to each other; and a good deal of horizontal movement may result from a sort of bouncing on the underside of the surface film. The Calanus in this zone are often aggregated into groups of a dozen or so which sometimes swim round and round each other like a group of mayflies. Both in these little swarms and on a larger scale, like most other plankton animals, they are extremely patchy in distribution. Frequently, after the tedious and complex preparations for diving, one finds that there is no zooplankton in the area at all and on other occasions there may be relatively few swarms, or shoals, with large stretches of empty water between them. This patchiness was amply confirmed by the variable results of hauls with plankton nets. 
Below the upper zone of $\mathrm{I} 2 \mathrm{in}$. is a second one of indeterminate depth. Animals are scarcer in this zone and are more uniformly distributed. They appear in about equal numbers swimming either vertically upwards or downwards and seem to be going to or from the upper layer. I was able to follow (separately) two or three individuals which left the upper layer, turning over and swimming vertically and steadily downwards for 5 or $6 \mathrm{ft}$., where they again turned upright and hung motionless for a short time before swimming steadily up again to the surface layer. Others swam up and down, presumably to and from greater depths, but I was only able to follow the few individuals making more shallow excursions. It may be that this deeper zone is one of migration between two more concentrated zones, the one at the surface and the other either just above the bottom or at some optimum level about 50 to $60 \mathrm{~m}$. down. Tow-nettings on these occasions certainly show animals in large numbers both at the surface and much deeper. It is reasonable to suppose that the whole population may be uniform and that there is a constant interchange between what are generally termed the 'surface' and 'deep' forms.

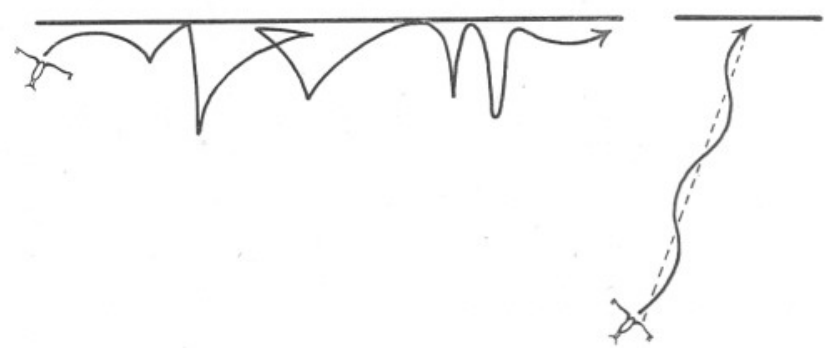

Fig. 2. Two types of swimming movement by Calanus.

An outstanding feature of all the populations observed was that, at any one time, as high a proportion as $50 \%$ would be quite motionless, most of these remaining so for long periods and many so delicately balanced as not to be even sinking in the water. On some occasions, especially when the sky was overcast, the whole population would be hanging motionless or drifting passively.

A clear horizontal migration by Calanus was seen only once. This occurred when there were very few specimens in view and the two seen, in the words of my diary, 'were just under the surface film and were moving horizontally by a series of oblique leaps and looping movements. They did not go deeper than about six inches. Horizontal progress was quite rapid and there were only very short motionless pauses' (Fig. 2). On the same occasion I watched another Calanus swim up about $3 \mathrm{ft}$., to the surface, in a rapid spiralling movement at an angle of about $30^{\circ}$ to the vertical.

Observations on animals other than Calanus were only incidental, but the following points may be of interest. 
Many smaller copepods were frequently seen in the upper 2 or 3 in. of water. These seemed to swim in an entirely random fashion with very little vertical and a good deal of horizontal movement.

Sagitta was common, generally exhibiting a very rapid vibration of the whole body, but showing little forward movement. I was able to make a record, on a piece of ground perspex, of the orientation of a specimen at $5 \mathrm{sec}$. intervals. This is reproduced in Fig. 3 and shows that, over a period of I min., the anterior end was generally pointing upwards but rarely vertically so.

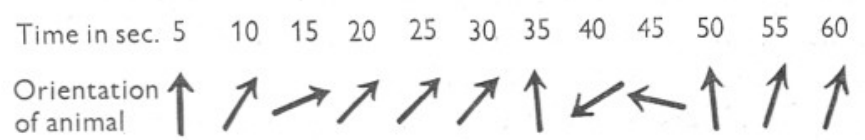

Fig. 3. Orientation of Sagitta sp. at $5 \mathrm{sec}$. intervals.

Coelenterates and ctenophores were almost always present and their swimming movements and the effect on these of such crude stimuli as touch were easily observed. A small gadoid associated with a medusa (probably Cyanea) was watched for some time and the fish was seen generally above the bell in an almost vertical position. It repeatedly sank down towards the bell and then swam up again (Fig. 4). The coelenterate was gently pulsating and the pair gradually drifted obliquely upwards. The fish showed no alarm and made no attempt to conceal itself under the bell during observation.

On another occasion large shoals of saith about 2 in. long were watched. The most striking feature about them was the constant very vigorous movement of the whole body. They again appeared undisturbed by observation unless I waved my arms in the midst of a shoal.

\section{Discussion}

It can be said with fair confidence that few of the animals observed were disturbed in any apparent way by the presence of the diver. Those which did show a reaction to his presence were the larger bottom-living fish and crustacea. The type of breathing set chosen shares, with all but those utilizing oxygen and absorbent salts, the disadvantage of releasing used air into the water. This, however, escapes behind the diver and only when he is breathing out. It is quite simple to regulate breathing so that, during crucial minutes, there is no air escaping. When it does so it causes no noticeable movement of 
the water and animals do not appear to react to it. The observations on the planktonic forms are therefore believed to be valid as records of their natural behaviour under the general environmental conditions mentioned. Calanus in particular showed a great preponderance of vertical movements in its swimming and it seems reasonable to deduce from this that the diurnal vertical migrations that it performs at other times of the year are a direct and straight swimming up or down through the water column, and not, as has been suggested by some authors, the result of random movements. A random type of swimming is, however, sometimes indulged in, particularly when near the surface film and when the population density is high. Those smaller copepods which are more often permanently at the surface seem more prone to swim in a random fashion. This behaviour may be a function of their very high population density.

However scientific and detached an account of the movement of these animals may be, it would be wrong not to make mention of the extraordinary beauty both of these forms and of their underwater surroundings. Experience of its richness and its strangeness would in itself be more than adequate reward for the discomfort and effort of diving.

\section{SUMMARY}

Attempts to make underwater observations on the movement of plankton animals using a modified frogman apparatus are described.

With practice, observation of even the smallest planktonic animals, under suitable conditions, is perfectly feasible.

Most data were obtained about individuals of the spring brood of Calanus inhabiting the surface layers. This population occupied two zones-an upper I2 in. where movement was generally a 'hop and sink' one and occasionally random, and a deeper zone where individuals were found swimming in equal numbers vertically upwards and downwards.

Calanus is often to be found in small swarms or clusters of a dozen or so individuals.

Smaller copepods and younger stages in the upper layers frequently indulge in a random motion.

\section{REFERENCES}

BAINBRIDGE, R., I949. Movement of zooplankton in diatom gradients. Nature, Vol. 163, p. 910.

BEEBE, W., I935. Half mile down. London.

Cushing, D. H., I951. The vertical migration of planktonic crustacea. Biol. Rev., Vol. 26, p. I58.

Dammant, G. C. C., I92I. Illumination of plankton. Nature, Vol. I08, p. 42.

HARDY, A. C. \& BAINBRIDGE, R., I95I. Vertical migration of plankton animals. Nature, Vol. 168, p. 327. [Substance of a paper read at the British Association.] 